\title{
Cardiorespiratory strain of a five day jogging relay
}

\author{
J Oksa, S Rissanen and V Martikkala* \\ Oulu Regional Institute of Occupational Health, Oulu and ${ }^{*}$ Oulu Deaconess Institute, Department of Sports \\ Medicine, Oulu, Finland
}

\begin{abstract}
The heart rates of 14 voluntary subjects (seven male and seven female) participating in a $5 \mathrm{~d}$ jogging relay were recorded. The jogging speed was controlled at $3.0 \mathrm{~m} \cdot \mathrm{s}^{-1}$ on average. The heart rate measurements were related to cardiorespiratory responses obtained during $\dot{\mathrm{VO}}_{2 \max }$ test on a treadmill. The mean(s.d.) $\mathrm{VO}_{2 \max }$ values were $53(2)$ and $48(2) \mathrm{ml} \cdot \mathrm{kg}^{-1} \cdot \mathrm{min}^{-1}$ and the anaerobic threshold was $42(1)$ and $38(2) \mathrm{ml} \cdot \mathrm{kg}^{-1} \cdot \mathrm{min}^{-1}$ for male and female subjects respectively. During the relay the mean(s.d.) heart rate values of male and female subjects were $150(1)$, and $167(3)$ beats $\min ^{-1}(P<0.001)$, corresponding to $68(1)$ and $76(2) \% \dot{V O}_{2 \max }(P<0.01)$ as calculated from the individual $\mathrm{HR} / \mathrm{VO}_{2}$ regression equations. The jogging time above anaerobic threshold heart rate level was $9(3) \%$ for the males and $43(7) \%$ for the females $(P<0.001)$ of the total jogging time. The results indicate that even in a leisure oriented jogging event, cardiorespiratory strain can be rather high and that the strain can be significantly higher for female than for male subjects. The determination of the anaerobic threshold as well as $\mathrm{VO}_{2 \text { max }}$ is important when quantifying the level of cardiorespiratory strain of exercise. (Br J Sports Med 1995; 29 : 165-167)
\end{abstract}

Keywords: heart rate; anaerobic threshold; cardiorespiratory strain; exercise

Several types of mass exercise events are popular in many countries, and many of these emphasize participation rather than performance. However, one cannot avoid a competitive tendency since participants determine their own pace. There is a Finnish mass jogging event in which the speed is deliberately kept low $\left(3.0 \mathrm{~m} \cdot \mathrm{s}^{-1}\right)$, thus giving a leisurely emphasis to the event. However, despite this slow speed, some participants are forced to drop out.

Research into cardiorespiratory strain during prolonged mass events, such as marathon running, has been conducted mainly on athletic subjects ${ }^{1}$; however, increasingly, interest has focused on non-athletic subjects. During various mass events the level of cardiorespiratory strain in physically active, but non-athletic, participants has been found to be comparable to those of well conditioned athletes. ${ }^{2} 3$

Cardiorespiratory strain in a purely leisure oriented mass event within a broad range of fitness levels is not well researched. Therefore, the aim of this study was to measure the heart rates of physically active, but nonathletic, male and female participants in a 5 day leisure

Address for correspondence: Juha Oksa, Oulu Regional Institute of Occupational Health, Aapistie 1, FIN-90220 Oulu, Finland oriented jogging relay; and to relate the heart rate values with measured maximum heart rates and oxygen consumption, as well as equivalent anaerobic threshold indices to evaluate the cardiorespiratory strain. Special attention was focused on possible differences between the sexes.

\section{Methods}

The Finnish jogging relay is a $1310 \mathrm{~km}$ long jogging event in which the participating teams run (day and night) for $5 \mathrm{~d}$ without pausing. The event is divided into 100 relay legs, the mean length of each being approximately $13 \mathrm{~km}$. The jogging speed is controlled by a car leading the event and the mean speed is approximately $3.0 \mathrm{~m} \cdot \mathrm{s}^{-1}$. During each leg small fluctuations in speed occur, so that it varies between 2.7 and $3.3 \mathrm{~m} \cdot \mathrm{s}^{-1}$.

The data for this study were collected during relays held in summer 1992 and 1993. In 1992 there were 150 and in 1993, 120 participating teams.

Fourteen subjects volunteered for the event, forming a group of males $(\mathrm{M}, n=7)$ and a group of females $(\mathrm{F}$, $n=7)$. Their written consent was obtained before the study. Table 1 summarizes their physical characteristics.

In 1992, three subjects were studied and in 1993, 11. During the relays the subjects ran between four and seven legs, with the exception of two women who ran one and three legs, respectively. The time of the day the subjects ran their legs was not standardized. The majority of the legs were run during the day (08.0021.00 ) and only $20 \%$ during the night. The recovery period between successive legs varied from 5 to $30 \mathrm{~h}$. However, on only five occasions did the recovery period take less than $10 \mathrm{~h}$. During the relay the diet of the subjects was not controlled but they were asked to eat as usual.

During every relay leg the heart rate (HR) of each subject was measured telemetrically in $60 \mathrm{~s}$ intervals

Table 1. Physical characteristics of the male $(n=7)$ and female $(n=7)$ subjects

\begin{tabular}{lrr}
\hline & Males & Females \\
\hline Weight $(\mathrm{kg})$ & $69(2)$ & $55(1)$ \\
Height $(\mathrm{cm})$ & $178(3)$ & $162(2)$ \\
Fat $(\%)^{4}$ & $13(2)$ & $23(1)$ \\
Age $(\mathrm{yr})$ & $35(7)$ & $28(5)$ \\
\hline
\end{tabular}

Values are means(s.d.) 
(Polar Sport Tester, Polar Electro). The heart rate recorder transmitter was attached to the chest of each subject by a belt, and receiver was on the wrist. Since the receivers were able to store eight blocks of data, all the data was transmitted to a computer after the relay. Before the relay the subjects were familiarized with the equipment. During the relay the subjects started their heart rate recording at the beginning of each leg and concluded it at the end of each leg.

At the midpoint, and at the end of each relay leg, the rating of perceived exertion (RPE) was recorded using a standard rating scale. ${ }^{5}$ The environmental conditions, ambient temperature, relative humidity, and average wind velocity were verified by the Institute of Meteorology for each area in which the relay was run.

After the relay, the measured heart rates were related to maximum heart rate $\left(\% \mathrm{HR}_{\max }\right)$ obtained from the maximum oxygen consumption test. A maximum oxygen consumption test $\left(\mathrm{VO}_{2 \text { max }}\right)$ was performed on a treadmill approximately 1 week after the relay. This test started at a speed of $1.75 \mathrm{~m} \cdot \mathrm{s}^{-1}$, and was increased by $0.25 \mathrm{~m} \cdot \mathrm{s}^{-1}$ (corresponding to a $3 \mathrm{ml} \cdot \mathrm{kg}^{-1} \cdot \mathrm{min}^{-1}$ theoretical increase in $\left.\mathrm{VO}_{2}\right)^{6}$ in 3 min intervals until exhaustion. Oxygen consumption (Medikro 202 ergospirometer) and heart rate were measured continuously. From their $\dot{\mathrm{VO}}_{2 \max }$ test, a $\mathrm{HR} / \mathrm{VO}_{2}$ regression equation was formed for each subject to determine their fractional $\mathrm{VO}_{2}$ utilization $\left(\% \dot{\mathrm{V}} \mathrm{O}_{2 \max }\right)$ during the relay. This method has been shown to be reasonably accurate and reliable when estimating mean fractional $\mathrm{VO}_{2}$ utilization. The anaerobic threshold level for each subject was determined by changes in ventilation and ventilatory quotient $\dot{\mathrm{VE}} / \mathrm{VO}_{2}$ according to Davies et al. ${ }^{8}$

The statistical significance of the data was tested with one way analysis of variance (ANOVA), and significance was accepted at the 0.05 level.

\section{Results}

The mean(s.d.) $\mathrm{VO}_{2 \max }$ values obtained from the treadmill test were $53(2)$ and $48(2) \mathrm{ml} \cdot \mathrm{kg}^{-1} \cdot \mathrm{min}^{-1}(\mathrm{NS})$ with corresponding maximum $\mathrm{HR}$ values of $188(3)$ and

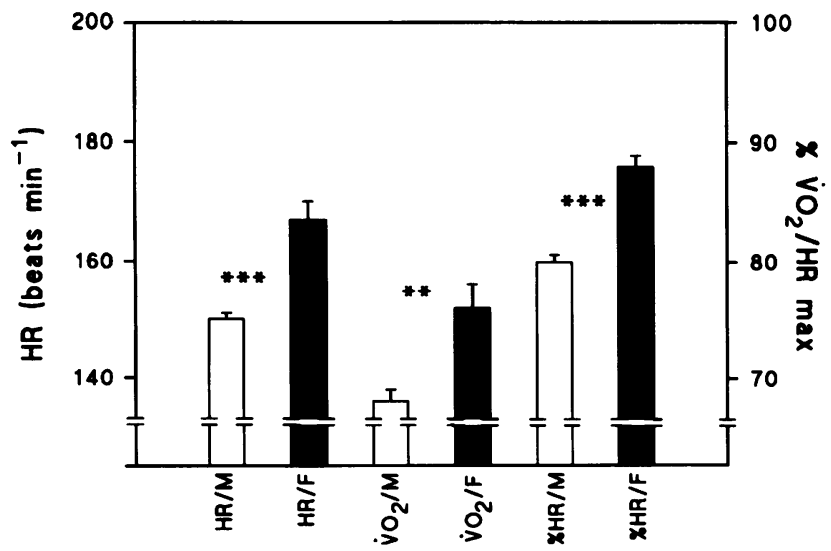

Figure 1. The mean heart rate, calculated fractional $\dot{\mathrm{V} O}$ utilization and $\% \mathrm{HR}_{\max }$ of male $\left(\mathrm{HR} / \mathrm{M}, \dot{\mathrm{VO}} \mathrm{O}_{2} / \mathrm{M}, \% \mathrm{HR} / \mathrm{M}\right)$ and female $\left(H R / F, \dot{V O}_{2} / F, \% H R / F\right)$ subjects

${ }^{* *}=P<0.01 ;{ }^{* * *}=P<0.001$
Table 2. The means(s.d.) values per relay leg for jogging time (J), jogging length (L) and time spent above anaerobic threshold $(>\mathrm{AT})$

\begin{tabular}{lcc}
\hline & Males & Females \\
\hline $\mathrm{J}_{\mathrm{t}}(\min )$ & $76(6)$ & $53(3)^{* *}$ \\
$\mathrm{~L}(\mathrm{~km})$ & $13.8(1.1)$ & $9.6(0.5)^{* *}$ \\
$>$ AT $(\min )$ & $6.7(2.3)$ & $22.7(3.8)^{* * *}$ \\
$>$ AT $(\%)$ & $8.8(3.1)$ & $42.8(7.0)^{* * *}$ \\
\hline
\end{tabular}

Values are mean(s.e.); ${ }^{* *}=P<0.01 ;{ }^{* * *}=P<0.001$

192(4) beats $\cdot \mathrm{min}^{-1}$ (NS) for male and female groups, respectively. The corresponding mean(s.d.) anaerobic threshold values were $42(1)$ and $38(2) \mathrm{ml} \cdot \mathrm{kg}^{-1} \cdot \mathrm{min}^{-1}$ $\left(\mathrm{ATVO}_{2}, \mathrm{NS}\right)$ and $\mathrm{HR}$ 166(3) and 174(5) beats $\cdot \mathrm{min}^{-1}$ (ATHR, NS).

During the relay legs ambient temperature varied between 11 and $20^{\circ} \mathrm{C}$, relative humidity was $38-96 \%$, and wind velocity $1-6 \mathrm{~m} \cdot \mathrm{s}^{-1}$.

The cardiorespiratory strain during the relay, expressed as mean $\mathrm{HR}, \% \mathrm{HR}_{\max }$ and $\% \dot{\mathrm{V}} \mathrm{O}_{2 \max }$, was significantly higher for females than males (Figure 1). The measured mean heart rate values during the relay legs varied interindividually between 140 and 181 beats $\cdot \min ^{-1}$. The intraindividual variation was $4-11$ beats $\cdot \mathrm{min}^{-1}$ in females and $4-14$ beats $\cdot \mathrm{min}^{-1}$ in males.

In the relay, men performed 38 relay legs and women 32 legs; and both groups had fairly similar terrain profiles. The total jogging time for men was $44 \mathrm{~h}$ and $20 \mathrm{~min}$ (corresponding to $483 \mathrm{~km}$ ), and for women $27 \mathrm{~h}$ (corresponding to $294 \mathrm{~km}$ ). The mean duration, length of each relay leg and the jogging time spent above AT (calculated as heart rate above ATHR level during jogging) were also significantly higher in the women (Table 2).

\section{Discussion}

When the heart rate levels measured were placed in the individual $\mathrm{HR} / \mathrm{VO}_{2}$ regression equations obtained from the maximal treadmill exercise test, the results showed high levels of cardiorespiratory strain in both groups (men $=68 \%$, women $=76 \%$ ). The present results are, however, lower than those observed by Oja et al ${ }^{2}$ $\left(85.7 \% \mathrm{VO}_{2 \text { max }}\right)$ during a self paced prolonged jogging event. The difference is due to the slow jogging speed of the relay.

The total exercise time spent above anaerobic threshold in this study was proportionately large (the mean of both groups together was $22 \%, n=14$ ). In addition, a striking difference (especially when considering the high fitness levels of the female subjects) was observed between the groups. The women spent significantly more time above anaerobic threshold level during jogging, and it is conceivable that this was caused by several factors. The calculated $\mathrm{VO}_{2}$ values during jogging for men were $36 \mathrm{ml} \cdot \mathrm{kg}^{-1} \cdot \mathrm{min}^{-1}$ and for women $36.5 \mathrm{ml} \cdot \mathrm{kg}^{-1} \cdot \mathrm{min}^{-1}$ and their $\mathrm{ATVO} \mathrm{O}_{2}$ values were 42 and $38 \mathrm{ml} \cdot \mathrm{kg}^{-1} \cdot \mathrm{min}^{-1}$, respectively. The differences between the groups within these variables was small and of no statistical significance; however, it 
is noteworthy that the women had a 'tolerance limit' of only $1.5 \mathrm{ml} \cdot \mathrm{kg}^{-1} \cdot \mathrm{min}^{-1}$ in exceeding anaerobic threshold, in comparison to $6 \mathrm{ml} \cdot \mathrm{kg}^{-1} \cdot \mathrm{min}^{-1}$ in the men. $\dot{\mathrm{VO}}_{2 \text { max }}$ in the women was only slightly lower (NS) in comparison to the men, but was still only one element causing the higher cardiorespiratory strain for female subjects.

Small fluctuations in jogging speed during the relay were observed $\left(2.7-3.3 \mathrm{~m}^{\cdot} \mathrm{s}^{-1}\right)$. Since the 'tolerance limit' in the women was so narrow, even a small increase in the jogging speed (or uphill jogging) may have momentarily caused the $\dot{\mathrm{VO}}_{2}$ to increase and therefore exceed the anaerobic threshold level.

It is also possible that gender differences in muscular force may have some significance. In relation to their body weight, women have been shown to have less muscle force. ${ }^{9}$ If the women in this study had less muscle force than the men then this factor could have caused a greater local strain on the working muscles (especially in uphill jogging) and caused the $1.5 \mathrm{ml} \cdot \mathrm{kg}^{-1} \cdot \mathrm{min}^{-1}$ 'tolerance limit' to be exceeded. Also, factors such as running economy may have an effect on the results. However, the higher level of cardiorespiratory strain observed in the women probably results from a combination of factors.

The measured differences in heart rate responses between the men and women were also reflected as higher ratings of perceived exertion in the women. The median ratings of perceived exertion in the midpoint of the relay legs were 12 and 10 for the women and men, respectively; the corresponding values at the end of the legs were 15 and 13.

The individual mean heart rates measured during the 5 day jogging relay did not show any consistent descending or ascending trend. This implies that the recovery time between adjacent relay legs was sufficient. The observed variations in the mean heart rate values during various relay legs may be due to terrain profiles and other ambient factors such as temperature, relative humidity, and wind velocity. If ambient factors had an additive effect on heart rate responses during the relay legs it means that the evaluated cardiorespiratory strain in this study may be slightly overestimated.

According to the equation of Mayhew, ${ }^{6}$ the oxygen consumption for the subject jogging on the level at a speed of $3.0 \mathrm{~m} \cdot \mathrm{s}^{-1}$ is approximately $35 \mathrm{ml} \cdot \mathrm{kg}^{-1} \cdot \mathrm{min}^{-1}$. For men, the calculated $\mathrm{VO}_{2}$ values during jogging were $36 \mathrm{ml} \cdot \mathrm{kg}^{-1} \cdot \mathrm{min}^{-1}$, and for women $36.5 \mathrm{ml} \cdot \mathrm{kg}^{-1} \cdot \mathrm{min}^{-1}$, which correspond well with the equation of Mayhew.

When considering the level of fitness needed for this event, it appears that in the women it was slightly too low. On the basis of these data it could postulated that an approximate anaerobic threshold value of $42 \mathrm{ml} \cdot \mathrm{kg}^{-1} \cdot \mathrm{min}^{-1}$ would be high enough to prevent long bouts of exercise spent above the threshold. If we take anaerobic threshold to be $80 \%$ of the maximum, as was the case in this study, it would mean that the $\dot{\mathrm{V}}{ }_{2 \max }$ of a participant should be approximately $52 \mathrm{ml} \cdot \mathrm{kg}^{-1} \cdot \mathrm{min}^{-1}$ in order to meet the demands of the event successfully.

In conclusion, the cardiorespiratory strain of physically active, but non-athletic, participants during a leisure oriented jogging event can be high, especially in women, thus emphasizing the need for training before an event. When evaluating the level of cardiorespiratory strain, it is important to know the individual anaerobic threshold as well as the $\mathrm{VO}_{2 \max }$ level.

\section{References}

I Sjödin B, Svedenhag J. Applied physiology of marathon running. Sport Med 1985 ; 2: 83-99.

2 Oja P, Kukkonen-Harjula R, Nieminen R, Vuori I, Pasanen M. Cardiorespiratory strain of middle-aged men in mass events of long-distances cycling, rowing, jogging and skiing. Int J Sports Med 1988; 9: 45-51.

3 Smolander J, Louhevaara V, Ahonen M. Clothing hypothermia and long-distance skiing. Lancet 1986; ii: 226-7.

4 Durnin JVGA, Rahaman MM. The assessment of the amount of fat in the human body from measurements of skinfold thickness. $\mathrm{Br} J$ Nutr 1967; 21 : 544-50.

5 Borg G. Perceived exertion as an indicator of somatic stress. Scand J Rehab Med 1970; 2 : 92-8.

6 Mayhew JL. Oxygen cost and energy expenditure of running in trained runners. $\mathrm{Br} J$ Sports Med 1977; 3: 116-21.

7 Oja P, Ilmarinen J, Louhevaara V. Heart rate as an estimator of oxygen consumption during manual postal delivery. Scand J Work Environ Health 1982 ; 8: 29-36.

8 Davies JA, Frank MH, Whipp BJ. Anaerobic threshold alternations caused by endurance training in middle-aged men. J Appl Physiol 1979; 49: 1039-46.

9 Willmore J. Alterations in strength, body composition and anthropometric measurements consequent to a 10-week weight training program. Med Sci Sports Exerc 1974; 2 : 133-38. 